\title{
The Three-Objective Optimization Model of Flexible Workshop Scheduling Problem for Minimizing Work Completion Time, Work Delay Time, and Energy Consumption
}

\author{
Neda Karim Ahangar, Majid Khalili, Hamed Tayebi
}

\begin{abstract}
In recent years, the optimal design of the workshop schedule has received much attention with the increased competition in the business environment. As a strategic issue, designing a workshop schedule affects other decisions in the production chain. The purpose of this thesis is to design a three-objective mathematical model, with the objectives of minimizing work completion time, work delay time and energy consumption, considering the importance of businesses attention to reduce energy consumption in recent years. The developed model has been solved using exact solution methods of Weighted Sum (WS) and Epsilon Constraint $(\mathcal{E})$ in small dimensions using GAMS software. These problems were also solved in large-scale problems with NSGA-II and SFLA meta-heuristic algorithms using MATLAB software in single-objective and multi-objective mode due to the NP-Hard nature of this group of large and real dimensional problems. The standard BRdata set of problems were used to investigate the algorithms performance in solving these problems so that it is possible to compare the algorithms performance of this research with the results of the algorithms used by other researchers. The obtained results show the relatively appropriate performance of these algorithms in solving these problems and also the much better and more optimal performance of the NSGA-II algorithm compared to the performance of the SFLA algorithm.
\end{abstract}

Keywords: energy consumption; flexible workshop scheduling; makespan; multi-objective optimization; NSGA-II Algorithm; SFLA Algorithm

\section{INTRODUCTION}

In recent years, the optimal design of the workshop schedule has attracted a lot of attention by the increased competition in the business environment. Workshop scheduling is defined as a strategic problem affecting other decisions in the production chain [1]. The workshop scheduling problem can be divided into two static and dynamic categories. In the static state, $\mathrm{n}$ work must be done on the $m$ machine while maintaining a certain sequence. Each task in this environment consists of different operations with the known processing time and processing path on machines [4]. The scheduler tries to optimally allocate a set of resources to a set of tasks to be performed over a period of time. The workshop schedule is a form of classical scheduling problem that has been widely considered in various fields of engineering sciences. Considering the importance of scheduling in workshop and production environments, there is a need for extensive research to address various aspects of the workshop scheduling problem. The flexible workshop flow problem is very common in the real world and has received a lot of attention in recent years. The main problem in the present research is to minimize the total work delay and energy consumption in flexible workshop scheduling problems. A metaheuristic or hybrid metaheuristic algorithms was used to solve this problem and the optimal solutions of each algorithm was compare with each other. Finally it is examined that which of the metaheuristic algorithms provides the best answer to solve the problem in this research. Also, in order to evaluate the efficiency of the method and model, a case study from industry is used in this study to examine the efficiency of the results in the real world. The present study solves the problem of flexible workshop flow scheduling by considering some real-world hypotheses that have not yet been explored. Considering the application of the problem in many production environments, this research can take a small step in solving this problem. The present research aimed to improve operations in the flexible workshop flow problem due to the importance of scheduling.

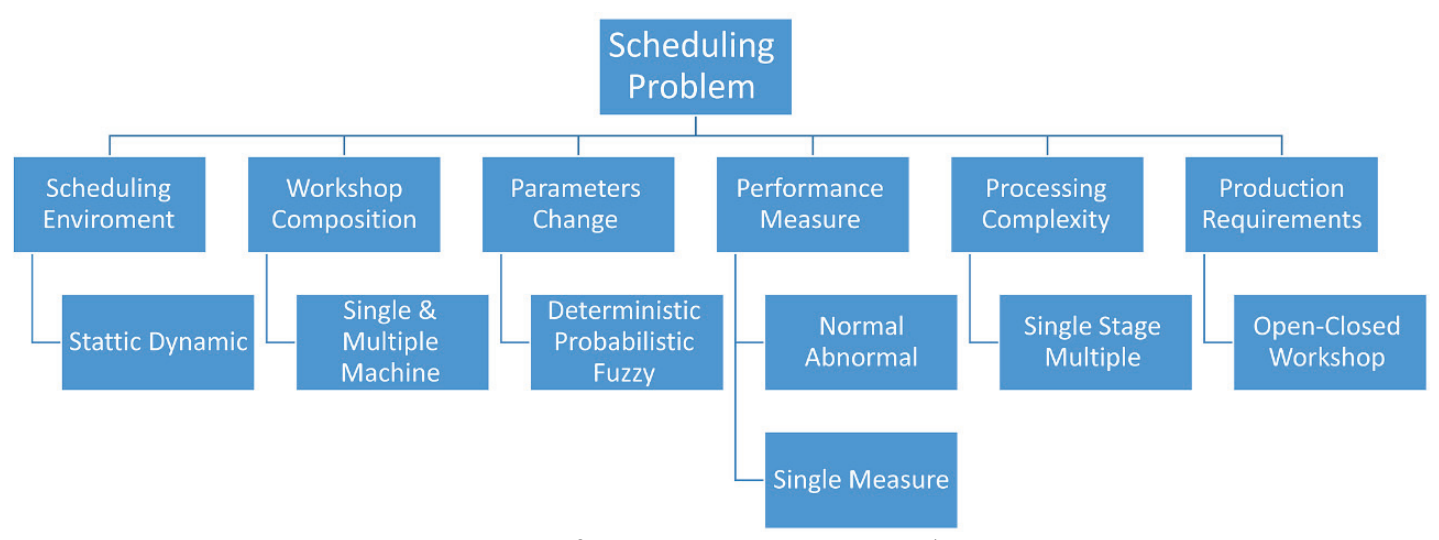

Figure 1 Categorizing scheduling problems [15] 


\section{LITERATURE REVIEW AND RESEARCH BACKGROUND}

The Flexible Workshop Flow Scheduling (FFS) Problem involves sequencing a workshop flow problem where there are at least one or more dissimilar parallel machines at each stage. The objective function of the problem is to minimize the maximum time to complete tasks [2]. Scheduling has been proposed as one of the new research fields since 1954 (Asadi et al., 2015). Scheduling is a decision-making process that plays an important role in production systems so that the performance criteria of any production system can be improved by an effective and efficient scheduling program [1].

Workshop scheduling can be classified into five main categories according to the workshop environment, single machine, parallel machines, workshop flow, closed workshop, and open workshop (Allahverdi and Soroush 2008, Hall 1998). All workshop scheduling issues belong to the NP-Hard class. Tab. 1 shows the types of scheduling issues.

Table 1 Some flexible workshop flow scheduling issues [13]

\begin{tabular}{|c|c|}
\hline Authors' name & Model description \\
\hline Jalalab \& Jalab, 2002 & Work permutation \\
\hline $\begin{array}{l}\text { Jungwattanakit et al., 2005, 2008, } \\
\text { 2009; Yuarima et al., } 2009\end{array}$ & $\begin{array}{l}\text { The problem of flexible workshop } \\
\text { flow with the assumption of } \\
\text { unrelated parallel machines }\end{array}$ \\
\hline $\begin{array}{l}\text { Kurz and Askin, 2004; } \\
\text { Logendran, Vo and Witt, 2007; } \\
\text { Jungwattanakit, 2008; Zandieh and } \\
\text { Gholami, 2009; Fattahi et al., } 2015\end{array}$ & $\begin{array}{l}\text { Sequence-dependent preparation on } \\
\text { machines }\end{array}$ \\
\hline $\begin{array}{l}\text { Riane et al., 2001; Alvi and Arbita, } \\
2004\end{array}$ & Transport between machines \\
\hline Naderi et al., 2009 & $\begin{array}{l}\text { Limited buffer capacity between } \\
\text { two consecutive steps }\end{array}$ \\
\hline Sawik, 2002; Akrami, 2006 & Prioritization of work \\
\hline Hentous and Benhammadi, 2006 & Maintenance constraints \\
\hline $\begin{array}{l}\text { BottaGenoulaz, 2000; Wu et al., } \\
2010\end{array}$ & Dynamic uncertainty \\
\hline $\begin{array}{l}\text { Aloe and Arbita, 2004; Aloe and } \\
\text { Arbita, } 2006\end{array}$ & $\begin{array}{l}\text { Prerequisite constraint between } \\
\text { tasks and wastage times constraint } \\
\text { between steps and with the } \\
\text { objective function of minimizing } \\
\text { the maximum latency }\end{array}$ \\
\hline $\begin{array}{l}\text { Hong and Wong, 2000; Alisantoso, } \\
2003\end{array}$ & $\begin{array}{l}\text { The capacity constraint of } \\
\text { intermediate warehouses without } \\
\text { considering it with the aim of } \\
\text { minimizing the maximum } \\
\text { completion time, the weighted total } \\
\text { time during construction and the } \\
\text { weighted total of delay times }\end{array}$ \\
\hline $\begin{array}{l}\text { Naderi et al., 2009; Janiak et al., } \\
\text { 2007; Behnamian and Zandieh, } \\
\text { 2011 }\end{array}$ & $\begin{array}{l}\text { The problem of flexible multi- } \\
\text { objective workshop flow }\end{array}$ \\
\hline
\end{tabular}

The problem of a flexible two-stage workshop flow with the same number of parallel machines in the first stage and one machine in the second stage has been investigated in Tran and Ming (2011), aimed at minimizing the maximum completion time. BottaGenoulaz (2000) examined the problem of flexible workshop flow with pre-requisite limit between tasks and waste time constraints between stages and with the objective function of minimizing the maximum latency and proposed six new innovative methods [3]. The flexible workshop flow problem with the objective function of sum of early and late with and waiting time and presented three metaheuristic algorithms and three constructive algorithms for it has been considered by Janiak et al. (2007). The problem of flexible workshop flow with limited waiting time and the objective function of the sum of early and late squares has been investigated by Behnamian and Zandieh (2011) that proposed a discrete colonial competition algorithm to solve it.

The problem of efficient multi-objective energy scheduling, with two objectives: completion time and energy consumption in production systems is developed by Dai et al. (2013) investigated. They used a measurement between completion time and energy consumption [14].

The problem of scheduling tasks in a flexible workshop environment have been investigated by Wang et al. (2018). Their objective function is the total energy consumption and their solution method is a two-step initiative that in the first and second stages have used genetic metaheuristic methods and particle swarm optimization, respectively. Also, a twoobjective model is presented by Wong et al. (2018) in which, they have scheduled parallel and identical machines whose goals are the total energy consumption and the time of completion of works. They have used the Epsilon constraint method to accurately solve their model [28].

A study on green planning during a two-machine workshop is presented by Mansouri et al. (2016) presented to examine the relationship between completion time and energy consumption. The developed mathematical model combines the main topics of the workshop: service level and energy consumption. The metaheuristic algorithms have been used to solve large-scale problems [39].

\section{RESEARCH METHOD}

The present study is an applied research conducted with analytical-descriptive approach. This research presents a multi-objective model of flexible workshop scheduling. The model developed in this research includes three important objectives of minimizing completion time, delay and energy consumption in workshop scheduling issues. The developed model is solved by the multi-objective meta-heuristic algorithm approach. This approach is used to solve multiobjective problems. The present research model includes three objective functions. One objective function seeks to reduce work completion time in workshop flow problems, and the second objective function seeks to minimize work delays; the last objective function seeks to minimize energy consumption levels due to the problems, shortages, and high energy costs in today's world.

The counters, decision variables and problem parameters used in this research are as follows:

\begin{tabular}{|l|c|}
\hline \multicolumn{2}{|c|}{ Indices and sets } \\
\hline Machine index, $i=1,2, \ldots, m$ & $i, i^{\prime}$ \\
\hline Work index, $j=1,2, \ldots, n$ & $j, j^{\prime}$ \\
\hline Operation index of each task, $h=1,2, \ldots, n_{j}$ & $h, h^{\prime}$ \\
\hline Processing speed index & $l$ \\
\hline $\begin{array}{l}\text { A set of machines capable of processing the operations of } j h \\
\text { work }\end{array}$ & $E_{j h}$ \\
\hline \multicolumn{2}{|c|}{ Parameters } \\
\hline
\end{tabular}




\begin{tabular}{|l|c|}
\hline Large positive number & $M$ \\
\hline Number of work operations $j$ & $n_{j}$ \\
\hline Delivery date $j$ & $d_{j}$ \\
\hline Processing time of $h^{\text {th }}$ operation of $j^{\text {th }}$ work on $i^{\text {th }}$ machine $i$ & $p_{j h i}$ \\
\hline Processing speed factor & $v_{l}$ \\
\hline Conversion factor for processing speed $l$ & $\alpha_{l}$ \\
\hline Conversion factor for machine idle time $i$ & $\beta_{i}$ \\
\hline \multicolumn{2}{|c|}{ Decision variables } \\
\hline Total completion time $\quad C_{\max }$ \\
\hline Total energy consumption in $\mathrm{kWh}$ & $T E C$ \\
\hline Total delay time & $T_{\max }$ \\
\hline Termination of $h^{\text {th }}$ operation of $j^{\text {th }}$ work on $i^{\text {th }}$ machine & $C_{j h i}$ \\
\hline The $i^{\text {th }}$ machine idle time & $\theta_{i}$ \\
\hline Work delay time $j$ & $T_{j}$ \\
\hline $\begin{array}{l}\text { It is a binary variable, it is } 1 \text { if the } h^{\text {th }} \text { operation of } j^{\text {th }} \text { work on } i^{\text {th }} \\
\text { machine is processed at speed } 1, \text { and zero, otherwise }\end{array}$ & $X_{j h i l}$ \\
\hline $\begin{array}{l}\text { It is a binary variable, it is } 1 \text { if the } h^{\text {th }} \text { operation of } j^{\text {th }} \text { work occurs } \\
\text { after the } h^{\text {th }} \text { operation of } j^{\text {th }} \text { work, and zero, otherwise }\end{array}$ & $Y_{j h j^{\prime} h^{\prime}}$ \\
\hline
\end{tabular}

Accordingly, the problem mathematical model will be as follows:

$$
\begin{aligned}
& \min z_{1}=C_{\max } \\
& \min z_{2}=T E C \\
& \min z_{3}=T_{\max } \\
& C_{j h i^{\prime}}-\sum_{i \in E_{j(h+1)}}\left(C_{j(h+1) i}-\sum_{l=1}^{L}\left(\frac{p_{j(h+1) i}}{v_{l}}\right) \times X_{j h i l}\right) \leq 0 \\
& \forall j, h<n_{j}, i^{\prime} \in E_{j h} \\
& C_{j h i}-\left(\frac{p_{j h i}}{v_{l}}\right)-C_{j^{\prime} h^{\prime} i} \geq \\
& \geq-M \times\left(2-X_{j h i l}-\sum_{l^{\prime}=1}^{L} X_{j^{\prime} h^{\prime} i l^{\prime}}\right)-M \times\left(1-Y_{j h j^{\prime} h^{\prime}}\right) \\
& \forall j<j^{\prime}, h, h^{\prime}, i, i^{\prime}, l \\
& C_{j^{\prime} h^{\prime} i}-\left(\frac{p_{j^{\prime} h^{\prime} i}}{v_{l}}\right)-C_{j h i} \geq \\
& \geq-M \times\left(2-\sum_{l^{\prime}=1}^{L} X_{j h i l^{\prime}}-X_{j^{\prime} h^{\prime} i l}\right)-M \times\left(1-Y_{j h j^{\prime} h^{\prime}}\right) \\
& \forall j<j^{\prime}, h, h^{\prime}, i, i^{\prime}, l \\
& \sum_{i \in E_{j h}} \sum_{l=1}^{L} X_{j h i l}=1 \quad \forall j, h \leq n_{j} \\
& C_{j h i} \leq M \times \sum_{l=1}^{L} X_{j h i l} \quad \forall j, h \leq n_{j}, i \in E_{j h} \\
& \sum_{i \in E_{j 1}}\left(C_{j 1 i}-\sum_{l=1}^{L}\left(\frac{p_{j 1 i}}{v_{l}}\right) \times X_{j 1 i l}\right) \geq 0 \quad \forall j \\
& C_{\max } \geq C_{j h i} \quad \forall j, h \leq n_{j}, i \in E_{j h}
\end{aligned}
$$

$$
\begin{aligned}
& \theta_{i}=C_{\max }-\sum_{j=1}^{n} \sum_{h=1}^{n_{j}} \sum_{l=1}^{L}\left(\frac{p_{j h i}}{v_{l}}\right) \times X_{j h i l} \quad \forall i \in E_{j h} \\
& T E C=\sum_{i \in E_{j h}} \sum_{j=1}^{n} \sum_{h=1}^{n_{j}} \sum_{l=1}^{L} \alpha_{l} \times\left(\frac{p_{j h i}}{v_{l}}\right) \times X_{j h i l}+\sum_{i=1}^{m} \beta_{i} \times \theta_{i} \\
& T_{j} \geq \sum_{i \in E_{j h}} C_{j h i}-d_{j} \quad \forall j, h=n_{j} \\
& T_{\max } \geq T_{j} \quad \forall j \\
& C_{j h i}, T_{j}, \theta_{i}, C_{\max }, T E C, T_{\max } \geq 0 \\
& X_{j h i l}, Y_{j h j^{\prime} h^{\prime}} \in\{0,1\}
\end{aligned}
$$

In the above model, the first objective function (1) maximizes the maximum completion time; the second objective function (2) minimizes the total energy consumption, and the third objective function (3) minimizes the maximum delay time. Constraint (4) causes that the operation of one task does not start until the next operation of that task is completed. Constraints (5) and (6) prevent interference of two operations on a machine. Based on constraint (7), the operation of each task is definitely processed on a machine at a certain speed. Constraint (8) shows the end time of each operation. Based on constraint (9), the completion time of the first operation of each task is a positive value. Constraint (10) indicates the maximum termination time. Constraint (11) indicates the unemployment rate of each machine. Constraint (12) calculates the total energy consumption. Constraint (13) and (14) calculates the amount of latency of each task and the maximum amount of latency, respectively. The constraint (15) shows the problem variables.

\section{Solving the mathematical models and problem analysis:}

The meta-heuristic algorithm has been used in this research. In the first step, the main input parameters of this algorithm must be set.

In this section, the input parameter for the NSGA-II algorithm must be adjusted. The experimental design and Taguchi method are used to design the parameter.

The parameters of this algorithm are as follows:

- nPop: Initial population size,

- $P c$ : Intersection probability,

- Pm: Mutation probability

- Maxit: Maximum number of repetitions.

The factors table is as follows:

Table 2 Important factors of NSGA-II algorithm

\begin{tabular}{|l|c|c|c|c|}
\hline \multirow{2}{*}{ Parameter } & \multirow{2}{*}{ Symbol } & \multicolumn{3}{c|}{ Levels } \\
\cline { 3 - 5 } & & 1 & 2 & 3 \\
\hline$n$ Pop & $\mathrm{A}$ & 30 & 50 & 70 \\
\hline$P c$ & $\mathrm{~B}$ & 0.65 & 0.75 & 0.99 \\
\hline Pm & $\mathrm{C}$ & 0.05 & 0.25 & 0.45 \\
\hline Maxit & $\mathrm{D}$ & 40 & 60 & 80 \\
\hline
\end{tabular}


The table is as follows for 4 factors in the three levels of Taguchi:

Table 3 Taguchi L-9 series
\begin{tabular}{|c|c|c|c|c|}
\hline No. of experiment & A & B & C & D \\
\hline 1 & 1 & 1 & 1 & 1 \\
\hline 2 & 2 & 2 & 2 & 1 \\
\hline 3 & 3 & 3 & 3 & 1 \\
\hline 4 & 3 & 2 & 1 & 2 \\
\hline 5 & 1 & 3 & 2 & 2 \\
\hline 6 & 2 & 1 & 3 & 2 \\
\hline 7 & 2 & 3 & 1 & 3 \\
\hline 8 & 3 & 1 & 2 & 3 \\
\hline 9 & 1 & 2 & 3 & 3 \\
\hline
\end{tabular}

\subsection{Evaluating the Algorithms Efficiency with Numerical Examples for Large-Scale Problems}

In this section, the efficiency of the proposed algorithms to solve the problem of this research will be investigated. The algorithms were coded using MATLAB 2019 and run on a system with $8 \mathrm{~GB}$ of internal storage and an $\mathrm{i} 7 \mathrm{CPU}$. In order to evaluate these algorithms in this research, a standard test data set called FJSPLIB, which is available at http://people.idsia.ch, has been used. In this set, standard test problems are used to evaluate the algorithms performance. There is a coded version that has a set of standard problems called Bardata, BRdata, Daudata and Huridata. In this research, Brdata Set has been used, which includes 10 sample problem groups as presented by Brandimart [1]:

Table 4 Specifications of standard problems in the BRdata set

\begin{tabular}{|c|c|c|c|c|}
\hline $\begin{array}{c}\text { Sample } \\
\text { problem } \\
\text { number in } \\
\text { BRdata }\end{array}$ & $\begin{array}{c}\text { Number of } \\
\text { jobs }\end{array}$ & $\begin{array}{c}\text { Number of } \\
\text { machines }\end{array}$ & $\begin{array}{c}\text { Total number } \\
\text { of operations }\end{array}$ & $\begin{array}{c}\text { Maximum } \\
\text { number of } \\
\text { machines }\end{array}$ \\
\hline MK01 & 10 & 6 & 55 & 3 \\
\hline MK02 & 10 & 6 & 58 & 6 \\
\hline MK03 & 15 & 8 & 150 & 5 \\
\hline MK04 & 15 & 8 & 90 & 3 \\
\hline MK05 & 15 & 4 & 106 & 2 \\
\hline MK06 & 10 & 15 & 150 & 5 \\
\hline MK07 & 20 & 5 & 100 & 5 \\
\hline MK08 & 20 & 10 & 225 & 2 \\
\hline MK09 & 20 & 10 & 240 & 5 \\
\hline MK10 & 20 & 15 & 240 & 5 \\
\hline
\end{tabular}

In this standard set designed by Brandimart (1993) [19], the parameters of each of the problems in this set are randomly generated between two limits using a uniform distribution. The number of jobs is from 10 to 20 , the number of machines is 4 to 15 , the number of operations for each job is 5 to 15 and the number of operations for all jobs is 55 to 241. All parameters related to this data set are shown separately in the table above

As these problems are standard and different researchers in different years have used this series of standard problems to evaluate the performance of their chosen algorithm in solving the flexible single-objective workshop scheduling problem by minimizing the completion time, so it is possible to compare the performance of these two algorithms. Research with this series of solutions in single-objective mode is also possible, so first the performance of these algorithms in solving single-objective problem has been examined to determine the performance of these two algorithms in comparison with other algorithms in the research literature and then, three research objectives have been used for solving problem to compare the performance of these two algorithms in relation to each other.

Table 5 The algorithms performance in solving standard problems ([19] Brandimart, 1993)

\begin{tabular}{|c|c|c|c|c|c|c|}
\hline $\begin{array}{c}\text { Sample } \\
\text { problem } \\
\text { number } \\
\text { in } \\
\text { BRdata } \\
\text { number } \\
\text { of } \\
\text { worker } \\
\times \\
\text { number }\end{array}$ & $\begin{array}{c}n \times m \\
\text { limit } \\
\text { and low } \\
\text { limit } \\
\text { (LB, }\end{array}$ & $\begin{array}{c}\text { MAPSO } \\
\text { method } \\
\text { (Nouiri } \\
\text { et al., } \\
2015)\end{array}$ & $\begin{array}{c}\text { Modified } \\
\text { Ant } \\
\text { Method } \\
\text { (IACO) } \\
\text { (Wang et } \\
\text { al, 2017) }\end{array}$ & $\begin{array}{c}\text { NSGA-II } \\
\text { algorithm } \\
\text { of the } \\
\text { present } \\
\text { study }\end{array}$ & $\begin{array}{c}\text { The } \\
\text { SFLA } \\
\text { algorithm } \\
\text { of the } \\
\text { present } \\
\text { study }\end{array}$ \\
\hline MK01 & $10 \times 6$ & 42,36 & 41 & 40 & 40 & 41 \\
\hline MK03 & $10 \times 6$ & 32,24 & 26 & 26 & 26 & 26 \\
\hline MK04 & $15 \times 8$ & 211,204 & 207 & 204 & 204 & 204 \\
\hline MK05 & $15 \times 4$ & 81,48 & 65 & 60 & 63 & 65 \\
\hline MK06 & $10 \times 15$ & 86,33 & 61 & 60 & 55 & 61 \\
\hline MK07 & $20 \times 5$ & 173,133 & 173 & 140 & 155 & 145 \\
\hline MK08 & $20 \times 10$ & 523 & 523 & 523 & 523 & 523 \\
\hline MK09 & $20 \times 10$ & 369,299 & 307 & 307 & 307 & 312 \\
\hline MK10 & $15 \times 20$ & 296,165 & 312 & 208 & 245 & 298 \\
\hline
\end{tabular}

Table 6 Time to solution and average results of the proposed algorithms

\begin{tabular}{|c|c|c|c|c|c|c|c|}
\hline $\begin{array}{c}\text { Sample } \\
\text { problem } \\
\text { number } \\
\text { in } \\
\text { BRdata }\end{array}$ & \multirow{2}{*}{$\begin{array}{c}\text { Best } \\
\text { answer } \\
\text { BKS }\end{array}$} & $\begin{array}{c}\text { IACO method } \\
\text { (Wang et al., }\end{array}$ & $\begin{array}{c}\text { NSGA-II } \\
\text { algorithm of } \\
\text { the present } \\
\text { study }\end{array}$ & \multicolumn{2}{|c|}{$\begin{array}{c}\text { The SFLA } \\
\text { algorithm of the } \\
\text { present study }\end{array}$} \\
\cline { 3 - 9 } & & CPU & $\begin{array}{c}\text { AVG } \\
\text { CM }\end{array}$ & CPU & $\begin{array}{c}\text { AVG } \\
\text { CM }\end{array}$ & CPU & $\begin{array}{c}\text { AVG } \\
\text { CM }\end{array}$ \\
\hline MK01 & 40 & 40.30 & 1.09 & 1.16 & 40.15 & 4.01 & 41.23 \\
\hline MK02 & 26 & 26.10 & 2.16 & 1.48 & 26.20 & 6.09 & 26.15 \\
\hline MK03 & 204 & 204 & 2.18 & 9.18 & 207 & 10.70 & 207.10 \\
\hline MK04 & 62 & 60 & 9.02 & 2.35 & 63.11 & 3.87 & 65.55 \\
\hline MK05 & 172 & 173.2 & 7.10 & 3.70 & 168.39 & 4.88 & 185 \\
\hline MK06 & 58 & 60.30 & 30.12 & 10.70 & 55.5 & 26.38 & 61.1 \\
\hline MK07 & 139 & 141.5 & 17.07 & 3.26 & 159 & 26.21 & 151 \\
\hline MK08 & 523 & 523 & 4.30 & 11.52 & 523 & 189.41 & 523 \\
\hline MK09 & 310 & 315.2 & 91.99 & 28.94 & 308.1 & 122.87 & 307.3 \\
\hline MK10 & 214 & 213.1 & 190.11 & 33.44 & 254.34 & 189.41 & 301.1 \\
\hline
\end{tabular}

In the table above, the upper and lower limit (LB, UB) is the optimal answer if the optimal answer found is timeconsuming for the completion time (Makespan), otherwise the upper and lower limit found is set yet. For example, in the MK08 problem series, the optimal solution is 523, which in this row is only 523, which indicates the same case, and both modified ant algorithms (Wang et al., 2017) called IACO and MAPSO method (Nouri et al., 2015) have been able to find the optimal solution; however, heuristic methods have only been able to find the near-optimal 555 solution, and for the rest of the standard problems in the table, the optimal solution has not yet been achieved. The research proposed algorithms are NSGA-II and SFLA, which have obtained acceptable results compared to other algorithms and in the MK08 series problem has also been able to obtain the optimal answer. In the following, the solution time and the average solution results obtained by these algorithms are discussed in order to evaluate the performance of the algorithms both in terms of optimal solution and in terms of solution time. 


\subsection{The Algorithms Performance in Solving the Proposed Multi-Objective Problem}

As mentioned earlier, the proposed mathematical model of the problem has three objectives: minimizing the total completion time (Makespan) $C_{\max }$ and the total delay time $T_{\max }$, and finally minimizing the total energy consumption to do the job displayed with TEC. NSGA-II and SFLA algorithms have been used to solve this three-objective model and Brdata standard problems have been used to solve this multi-objective model. The status of Pareto answers is as follows, which shows the better performance of NSGA-II algorithm than the SFLA algorithm.
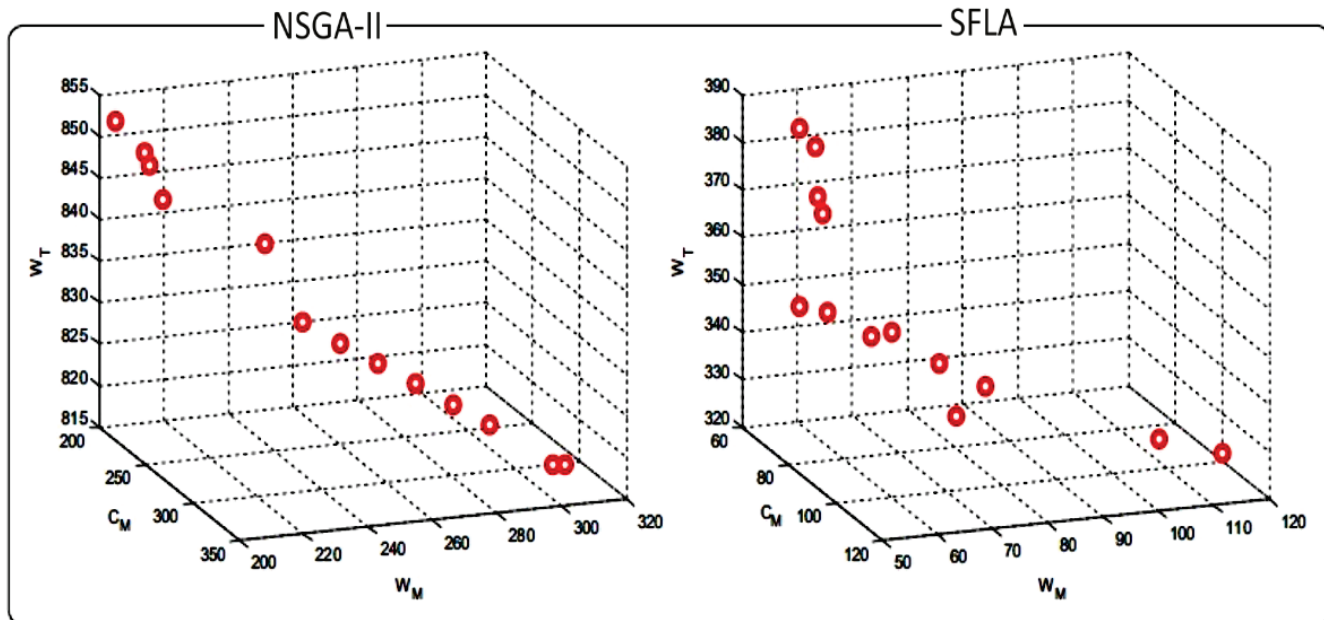

Figure 2 Pareto front set of answers found by the two studied algorithms

The results of the problem objective functions by these two algorithms are provided to solve these standard problems.

Table 7 Results of the algorithms performance in solving the three-objective problem

\begin{tabular}{|c|c|c|}
\hline Name of problem & NSGA-II algorithm & SFLA algorithm \\
\hline \multicolumn{3}{|c|}{ MK01 } \\
\hline$C_{\max }$ & 40 & 40 \\
\hline$T_{\max }$ & 167 & 169 \\
\hline TEC & 36 & 36 \\
\hline \multicolumn{3}{|c|}{ MK02 } \\
\hline$C_{\max }$ & 26 & 26 \\
\hline$T_{\max }$ & 151 & 151 \\
\hline TEC & 26 & 26 \\
\hline \multicolumn{3}{|c|}{ MK03 } \\
\hline$C_{\max }$ & 204 & 204 \\
\hline$T_{\max }$ & 855 & 852 \\
\hline TEC & 199 & 204 \\
\hline \multicolumn{3}{|c|}{ MK04 } \\
\hline$C_{\max }$ & 61 & 66 \\
\hline$T_{\max }$ & 345 & 366 \\
\hline TEC & 63 & 61 \\
\hline \multicolumn{3}{|c|}{ MK05 } \\
\hline$C_{\max }$ & 173 & 172 \\
\hline$T_{\max }$ & 683 & 687 \\
\hline TEC & 173 & 172 \\
\hline \multicolumn{3}{|c|}{ MK06 } \\
\hline$C_{\max }$ & 62 & 65 \\
\hline$T_{\max }$ & 424 & 398 \\
\hline$T E C$ & 55 & 62 \\
\hline \multicolumn{3}{|c|}{ MK07 } \\
\hline$C_{\max }$ & 139 & 140 \\
\hline$T_{\max }$ & 693 & 695 \\
\hline TEC & 139 & 140 \\
\hline \multicolumn{3}{|c|}{ MK08 } \\
\hline$C_{\max }$ & 523 & 523 \\
\hline$T_{\max }$ & 2524 & 2524 \\
\hline TEC & 515 & 523 \\
\hline
\end{tabular}

\begin{tabular}{|c|c|c|}
\hline Name of problem & NSGA-II algorithm & SFLA algorithm \\
\hline \multicolumn{3}{|c|}{ MK09 } \\
\hline$C_{\max }$ & 311 & 310 \\
\hline$T_{\max }$ & 2290 & 2294 \\
\hline$T E C$ & 299 & 301 \\
\hline \multicolumn{3}{|c|}{ MK10 } \\
\hline$C_{\max }$ & 214 & 214 \\
\hline$T_{\max }$ & 2053 & 2082 \\
\hline$T E C$ & 204 & 210 \\
\hline
\end{tabular}

Based on the above table, the results obtained in the objective functions, and as all objectives are minimization, it can be concluded that the relative performance of NSGA-II algorithm in solving this proposed problem than SFLA algorithm is more appropriate, so that in all objectives such as minimizing completion time and energy costs, this algorithm performs much more better than the SFLA algorithm and achieves better results.

\subsection{Sensitivity Analysis of NSGA-II Algorithm Parameters}

Sensitivity analysis was performed for the NSGA-II multi-objective algorithm as in the single-objective mode. The standard MK02 problem has been solved with different parameters of this algorithm in different modes. Four levels are considered by Taguchi method using each of the main parameters of this algorithm such as $n P o p, P c, P m$ and Maxit.

Table 8 Sensitivity analysis of NSGA-II algorithm parameters

\begin{tabular}{|c|c|c|c|c|c|}
\hline \multirow{2}{*}{ Parameter name } & Parameter & \multicolumn{3}{|c|}{ Level } & \\
\cline { 3 - 6 } & change interval & 1 & 2 & 3 & 4 \\
\hline$n$ Pop & $150-50$ & 50 & 75 & 100 & 150 \\
\hline$P c$ & $0.9-0.6$ & 0.60 & 0.7 & 0.75 & 0.9 \\
\hline Pm & $0.5-0.05$ & 0.05 & 0.1 & 0.25 & 0.5 \\
\hline Maxit & $100-10$ & 10 & 30 & 60 & 100 \\
\hline
\end{tabular}


The following table also shows the Design of Experiments (DOE) of each orthogonal array.

Table 9 Sensitivity analysis of NSGA-II algorithm parameters

\begin{tabular}{|c|c|c|c|c|c|}
\hline \multirow{3}{*}{$\begin{array}{c}\begin{array}{c}\text { No. of } \\
\text { experiment }\end{array} \\
29.4\end{array}$} & \multicolumn{4}{|c|}{ Factor level number } & \multirow{3}{*}{$\begin{array}{c}\begin{array}{c}\text { Average } \\
\text { amount of } C_{\max }\end{array} \\
\text { Maxit } \\
28.8\end{array}$} \\
\hline & \multirow{2}{*}{$\frac{P m}{29.4}$} & \multicolumn{2}{|c|}{$P c$} & \multirow{2}{*}{$\frac{n P o p}{1}$} & \\
\hline & & 3 & 1 & & \\
\hline 28.2 & 28.2 & 4 & 2 & 1 & 29.4 \\
\hline 27.8 & 27.8 & 2 & 3 & 1 & 28.2 \\
\hline 29.2 & 29.2 & 1 & 4 & 1 & 27.8 \\
\hline 28.8 & 28.8 & 2 & 1 & 2 & 29.2 \\
\hline 29.0 & 29.0 & 3 & 2 & 2 & 28.8 \\
\hline 28.8 & 28.8 & 4 & 3 & 2 & 29.0 \\
\hline 28.4 & 28.4 & 1 & 4 & 2 & 28.8 \\
\hline 28.8 & 28.8 & 1 & 1 & 3 & 28.4 \\
\hline 28.8 & 28.8 & 2 & 2 & 3 & 28.8 \\
\hline 28.6 & 28.6 & 3 & 3 & 3 & 28.8 \\
\hline 29.4 & 27.6 & 4 & 4 & 3 & 28.6 \\
\hline 27.6 & 28.6 & 3 & 1 & 4 & 27.6 \\
\hline 28.6 & 29.0 & 1 & 2 & 4 & 28.6 \\
\hline 29.0 & 28.8 & 4 & 3 & 4 & 28.8 \\
\hline 28.8 & 28.8 & 2 & 4 & 4 & 29.4 \\
\hline
\end{tabular}

Table 10 The change rate (Delta) of each parameter

\begin{tabular}{|c|c|c|c|c|}
\hline Factor & $n$ Pop & Maxit & $P c$ & $P m$ \\
\hline 1 & 28.55 & 28.60 & 28.50 & 28.40 \\
\hline 2 & 28.95 & 28.30 & 28.90 & 28.75 \\
\hline 3 & 28.65 & 28.65 & 28.75 & 28.50 \\
\hline 4 & 28.50 & 28.80 & 28.50 & 29.00 \\
\hline $\begin{array}{c}\text { (Delta) } \\
\text { changes }\end{array}$ & 0.45 & 0.50 & 0.40 & 0.60 \\
\hline
\end{tabular}

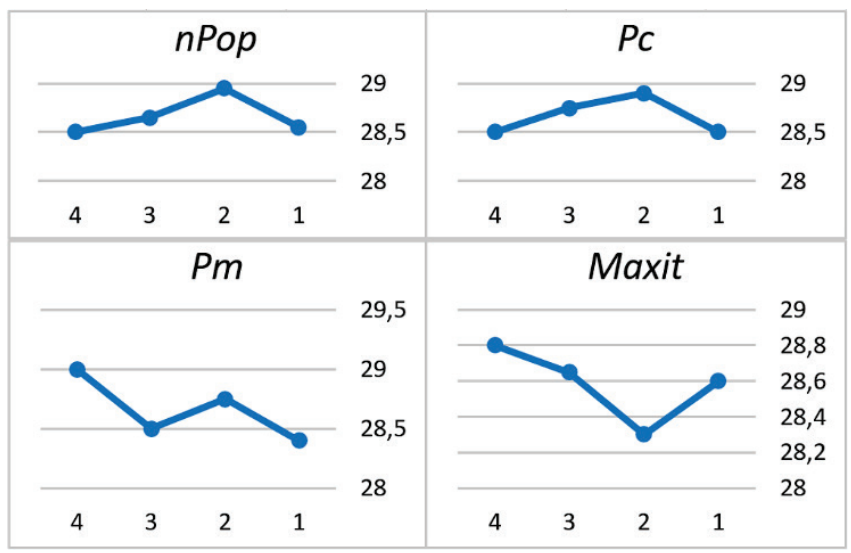

Figure 3 Sensitivity analysis of NSGA-II algorithm parameters

Tab. 10 also indicates the amount of change (Delta) of each parameter of the NSGA-II algorithm. The results of this table shows that the Pm parameter is the most effective parameter and the Maxit parameter is the second most effective parameter after $\mathrm{Pm}$ and PC parameter is the least effective parameter. Therefore, the Pm parameter is the most important and effective parameter in the NSGA-II algorithm in the series of flexible multi-objective workshop scheduling problems.

\section{CONCLUSION}

The present study aimed to develop a multi-objective mathematical model in the field of flexible workshop flow scheduling. Various optimization techniques have been used in order to achieve the research objectives. In the first step, a set of the problem hypotheses, constraints, and objectives were formulated mathematically. The resulting multiobjective model, as mentioned earlier, is one of the NP-Hard problems that can be solved only in small sizes with exact mathematical methods using GAMS IDE/Cplex software. However, since real-world problems are often larger and more complex, meta-heuristic algorithms were used to solve large problems. Two powerful multi-objective algorithms, namely NSGA-II and SFLA, were also used in this study on a large scale. A set of standard problems in the research literature called BRdata were also used to evaluate the performance of this algorithm, which all researchers around the world use to evaluate their developed methods and solution algorithms. The results show the optimal performance of these algorithms compared to other algorithms used in previous research. The NSGA-II algorithm also performed better than the SFLA algorithm. MATLAB program has been used to code meta-heuristic algorithms. In order to adjust the parameters of the algorithms, the well-known Taguchi method has been used. In addition, according to the sensitivity analysis of algorithms and their performance, the more effective parameter in the performance results of this algorithm in the superior NSGA-II algorithm is the parameter $\mathrm{pm}$. The following issues can be addressed in the future research:

- Developing a mathematical model with items such as adding some constraints such as availability of machinery, possible failure of machinery, start-up time etc.

- Using other new metaheuristic and hybrid algorithms to solve these problems

- Developing new methods such as nonlinear regression and neural network model and neural-fuzzy networks such as FIS and ANFIS, etc. to predict the maximum completion time and new approaches in solving these problems

- Applying other Pareto-based multi-objective methods such as NRGA and SPEA2 for the present research problem

- Coding the problem with other programming languages such as JAVA, etc. and evaluating the performance results

- Using the proposed mathematical model to a real problem in the industry and reviewing the results

- Solving other existing standard models (Bardata, Daudata, and Huridata) in the research literature with the proposed algorithms and comparing their performance in solving single-objective and multi-objective problems.

\section{REFERENCES}

[1] Alaykyran, K., Engin, O., \& Doyen, A. (2007). Using ant colony optimization to solve hybrid flow shop scheduling problems. Int J Adv Manuf Techno, 35, 541-550. https://doi.org/10.1007/s00170-007-1048-2

[2] Behnamian, J. \& Zandieh, M. (2011). A discrete colonial competitive algorithm for hybrid flowshop scheduling to 
minimize earliness and quadratic tardiness penalties. Expert Systems with Applications, 38, 14490-14498. https://doi.org/10.1016/j.eswa.2011.04.241

[3] Azar, A. \& Sadeghi, A. (2020). Service Supply Chain and its Performance Evaluation. Saffar Publications, ISBN: 978-964388-587-8.

[4] Jenabi, M., Fatemi-Ghomi, S. M. T., Torabi, S. A., \& Karimi, B. (2007). Two hybrid metaheuristics for the finite horizon elsp in flexible flow lines with unrelated parallel machines. Applied Mathematics and Computation, 186(1), 230-245. https://doi.org/10.1016/j.amc.2006.06.121

[5] Khalouli, S., Ghedjati, F., \& Hamzaoui, A. (2010). A metaheuristic approach to solve a JIT scheduling problem in hybrid flow shop. Engineering Applications of Artificial Intelligence, 23, 765-771. https://doi.org/10.1016/j.engappai.2010.01.008

[6] Kaplanoğlu, V. (2016). An object-oriented approach for multiobjective flexible job-shop scheduling problem. Expert Systems with Applications, 45(1), 71-84. https://doi.org/10.1016/j.eswa.2015.09.050

[7] Gen, M. \& Lin, L. (2014). Multiobjective evolutionary algorithm for manufacturing scheduling problems: state-ofthe-art survey. Journal of Intelligent Manufacturing, 25(5), 849-866. https://doi.org/10.1007/s10845-013-0804-4

[8] Li, J., Pan, Q., \& Xie, S. (2012). An effective shuffled frogleaping algorithm for multi-objective flexible job shop scheduling problems. Applied Mathematics and Computation, 218(18), 9353-9371. https://doi.org/10.1016/j.amc.2012.03.018

[9] Wang, J.-J. \& Liu, Y.-J. (2014). Single-machine bicriterion group scheduling with deteriorating setup times and job processing times. Applied Mathematics and Computation, 242, 309-314. https://doi.org/10.1016/j.amc.2014.05.048

[10] Wang, L., Wang, S., \& Liu, M. (2013). A Pareto-based estimation of distribution algorithm for the multi-objective flexible jobshop scheduling problem. International Journal of Production Research, 51(12), 3574-3592. https://doi.org/10.1080/00207543.2012.752588

[11] Wang, L., Zhou, G., Xu, Y., \& Liu, M. (2019). An enhanced Paretobased artificial bee colony algorithm for the multiobjective flexible job-shop scheduling. The International Journal of Advanced Manufacturing Technology, 60(9-12), 1111-1131. https://doi.org/10.1007/s00170-011-3665-z

[12] Zeballos, L. J. (2010). A constraint programming approach to tool allocation and production scheduling in flexible manufacturing systems. Robotics and Computer-Integrated Manufacturing, 26(6), 725-743. https://doi.org/10.1016/..rcim.2010.04.005

[13] Driss, I., Mouss, K. N., \& Laggoun, A. (2015). A new genetic algorithmfor flexible job-shop scheduling problems. Journal of Mechanical Science and Technology, 29(3), 1273-1281. https://doi.org/10.1007/s12206-015-0242-7

[14] Wu, X. L. \& Wu, S. M. (2015). An elitist quantum-inspired evolutionary algorithm for the flexible job-shop scheduling problem. Journal of Intelligent Manufacturing, 26(2), 1-7.

[15] Gao, K. Z., Suganthan, P. N., Chua, T. J., Chong, C. S., Cai, T. X., \& Pan, Q. K. (2015). A two-stage artificial bee colony algorithm scheduling flexible job-shop scheduling problem with new job insertion. Expert Systems with Applications, 42(21), 7652-7663. https://doi.org/10.1016/j.eswa.2015.06.004

[16] Brandimarte, P. (1993). Routing and scheduling in a flexible job shop by tabu search. Ann Oper Res, 41, 157-183. https://doi.org/10.1007/BF02023073

[17] Artigues, C. \& Feillet, D. (2008). A branch and bound method for the job-shop problem with sequence-dependent setup times. Ann Oper Res, 159(1), 135-159. https://doi.org/10.1007/s10479-007-0283-0
[18] Bagheri, A., Zandieh, M., Mahdavi, I., \& Yazdani, M. (2010). An artificial immune algorithm for the flexible job-shop scheduling problem. Future Gener Comput Syst, 26(4), 533541. https://doi.org/10.1016/j.future.2009.10.004

[19] Balaraju, G., Venkatesh, S., \& Reddy, B. S. P. (2014). Multiobjective flexible job shop scheduling using hybrid differential evolution algorithm. Int J Internet Manuf Serv, 3(3), 226-243. https://doi.org/10.1504/IJIMS.2014.062436

[20] Sadeghi, A., Azar, A., Valmohammadi, Ch., \& Alirezaei, A. (2020). Designing a product-service supply chain performance evaluation model in the home appliance industry. Production and Operations Management, 10(2), 83-123.

[21] Chiang, T. C. \& Lin, H. J. (2013). A simple and effective evolutionary algorithm for multiobjective flexible job shop scheduling. Int J Prod Econ, 141(1), 87-98. https://doi.org/10.1016/j.ijpe.2012.03.034

[22] Cwiek, M. \& Nalepa, J. (2014). A fast genetic algorithm for the flexible job shop scheduling problem. Proceedings of the 2014 conference companion on Genetic and evolutionary computation companion, ACM. 1449-1450. https://doi.org/10.1145/2598394.2602280

[23] Deb, K., Pratap, A., Agarwal, S., \& Meyarivan, T. A. M. T. (2002). A fast and elitist multiobjective genetic algorithm: NSGA-II. IEEE Trans Evol Comput, 6(2), 182-197. https://doi.org/10.1109/4235.996017

[24] Defersha, F. M. \& Chen, M. (2010). A parallel genetic algorithm for a flexible job-shop scheduling problem with sequence dependent setups. Int $J$ Adv Manuf Technol, 49(1-4), 263-279. https://doi.org/10.1007/s00170-009-2388-x

[25] Della Croce, F., Ghirardi, M., \& Tadei, R. (2002). An improved branch-and-bound algorithm for the two machine total completion time flow shop problem. Eur J Oper Res, 139(2), 293-301. https://doi.org/10.1016/S0377-2217(01)00374-5

[26] Gao, K. Z., Suganthan, P. N., Pan, Q. K., et al. (2014). Paretobased grouping discrete harmony search algorithm for multiobjective flexible job shop scheduling. Inf Sci (1), 76-90. https://doi.org/10.1016/j.ins.2014.07.039

[27] Geiger, C. D., Uzsoy, R., \& Aytuğ, H. (2006). Rapid modeling and discovery of priority dispatching rules: An autonomous learning approach. J Sched, 9(1), 7-34. https://doi.org/10.1007/s10951-006-5591-8

[28] Gen, M., Tsujimura, Y., \& Kubota, E. (1994). Solving job-shop scheduling problems by genetic algorithm. IEEE International Conference on Systems, Man, and Cybernetics, Humans, Information and Technology, 2, 77-82. https://doi.org/10.1109/ICSMC.1994.400072

[29] Heger, J., Branke, J., Hildebrandt, T. et al. (2016). Dynamic adjustment of dispatching rule parameters in flow shops with sequence-dependent set-up times. Int J Prod Res, 1-13. https://doi.org/10.1080/00207543.2016.1178406

[30] Jia, S. \& Hu, Z. H. (2014). Path-relinking Tabu search for the multi-objective flexible job shop scheduling problem. Comput Oper Res, 47, 11-26. https://doi.org/10.1016/j.cor.2014.01.010

[31] Sadeghi, A., Kalanaki, A., Noktehdan, A., Samghabadi, A. S., \& Barzinpour, F. (2011). Using Bees Algorithm to Solve the Resource Constrained Project Scheduling Problem in PSPLIB. Theoretical and Mathematical Foundations of Computer Science, 486-494. https://doi.org/10.1007/978-3-642-24999-0_67

[32] Kacem, I., Hammadi, S., \& Borne, P. (2002). Approach by localization and multiobjective evolutionary optimization for flexiblejob-shop scheduling problems. IEEE Trans Syst Man Cybern Part C Appl Rev, 32(1), 1-13. https://doi.org/10.1109/TSMCC.2002.1009117 
[33] Li, Y. \& Chen, Y. (2014). An improved genetic algorithm of Bi-level coding for flexible job shop scheduling problems. $J$ Netw, 9(7), 1783-1789. https://doi.org/10.4304/jnw.9.7.1783-1789

[34] Li, H. \& Zhang, Q. (2009). Multiobjective optimization problems with complicated Pareto sets, MOEA/D and NSGAII. IEEE Trans Evol Comput, 13(2), 284-302. https://doi.org/10.1109/TEVC.2008.925798

[35] Li, J. Q., Pan, Q. K., \& Liang, Y. C. (2010). An effective hybrid tabu search algorithm for multi-objective flexible job-shop scheduling problems. Comput Indust Eng, 59(4), 647-662. https://doi.org/10.1016/j.cie.2010.07.014

[36] Li, J. Q., Pan, Q. K., Suganthan, P. N. et al (2011). A hybrid tabu search algorithm with an efficient neighborhood structure for the flexible job shop scheduling problem. Int $J$ Adv Manuf Technol, 52(5-8), 683-697. https://doi.org/10.1007/s00170-010-2743-y

[37] Moghadam, A. M., Wong, K. Y., \& Piroozfard, H. (2014). An efficient genetic algorithm for flexible job-shop scheduling problem. IEEE International Conference on Industrial Engineering and Engineering Management, 1409-1413. https://doi.org/10.1109/IEEM.2014.7058870

[38] Mouelhi-Chibani, W. \& Pierreval, H. (2010). Training a neural network to select dispatching rules in real time. Comput Indus Eng, 58(2), 249-256. https://doi.org/10.1016/j.cie.2009.03.008

[39] Pezzella, F., Morganti, G., \& Ciaschetti, G. (2008). A genetic algorithm for the flexible job-shop scheduling problem. Comput Oper Res, 35(10), 3202-3212. https://doi.org/10.1016/j.cor.2007.02.014

\section{Authors' contacts:}

Neda Karim Ahangar, MSc Student

Department of Industrial Engineering, College of Engineering,

Karaj Branch, Islamic Azad University, Karaj, Iran

negar.karim.ahangar@gmail.com

Majid Khalili, Assistant Professor, Dr.

(Corresponding author)

Department of Industrial Engineering, College of Engineering,

Karaj Branch, Islamic Azad University, Karaj, Iran

Hamed Tayebi, Assistant Professor, Dr.

Department of Industrial Engineering, College of Engineering,

Karaj Branch, Islamic Azad University, Karaj, Iran 